\title{
Study of Phonological Awareness of Preschool and School Aged Children with Cochlear Implant and Normal Hearing
}

\author{
Niloufar Rastegarianzadeh ${ }^{1}$, Mohammadrahim Shahbodaghi ${ }^{2}$, and Soghrat Faghihzadeh ${ }^{3}$ \\ 'Department of Speech Therapy, Shiraz University of Medical Sciences, School of Rehabilitation, Shiraz, \\ 2Department of Speech Therapy, Tehran University of Medical Sciences, School of Rehabilitation, Tehran, \\ ${ }^{3}$ Department of Statistics, Tarbiat Modares University, Tehran, Iran
}

Received January 25,2014

Revised April 30, 2014

Accepted May 25, 2014

Address for correspondence
Niloufar Rastegarianzadeh, MS
Department of Speech Therapy,
Shiraz University of Medical
Sciences, School of Rehabilitation,
Shiraz, Iran
Tel + 987116271551
Fax +987116272495
E-mail niloufar.rastegarianzadeh
$\quad$ @gmail.com

Background and Objectives: The primary purpose of this study was to assess whether very early access to speech sounds provided by the cochlear implant enables children to develop age-appropriate phonological awareness abilities in their preschool and school years. A secondary purpose of this study was to examine whether children who had cochlear implantation before 18 months of age will develop better skills in phonological awareness than children who had cochlear implants in 18-36 months of age. A third purpose of this study was to examine whether some factors like the child's age or sex would have any effects on developing of ageappropriate phonological awareness abilities. Subjects and Methods: 48 children with 70 to 95 months of age who had been utilizing their cochlear implant(s) before 36 months of age $(\mathrm{Cl}$ group) and 30 normal hearing peers (NH group) were enrolled in this study. Results: Child's age had a significant effect on phonological awareness, but sex had absolutely no effect in each group. Children in the cochlear implanted group were outperformed by their normal hearing peers in the area of phonological awareness, especially in phonemic awareness. The age of implantation was another significant variable. Conclusions: Although children with a younger age at implantation got better scores in phonological awareness test, they were outperformed by their normal hearing peers in this area.

Korean J Audiol 2014;18(2):50-53 School aged.

\section{Introduction}

Studies have indicated that with early use of cochlear implants, many children who are deaf have been able to develop language and literacy skills that are within normal limits (i.e., within one standard deviation of the mean) when compared to their peers with normal hearing. ${ }^{1-4)}$ Other studies have indicated that children with cochlear implant have weakness in phonological awareness skills. ${ }^{5,6)}$ For those children who communicate using oral language, these improvements are often apparent before entry into elementary school. ${ }^{7,8)}$ Literacy studies are only beginning to emerge and have almost exclusively examined the reading skills of school-age children. ${ }^{4,59}$ Thus,

This is an Open Access article distributed under the terms of the Creative Commons Attribution Non-Commercial License (http://creativecommons org/licenses/by-nc/3.0/) which permits unrestricted non-commercial use, distribution, and reproduction in any medium, provided the original work is properly cited. they evaluate the interaction between cochlear implant use and formal literacy instruction. It is well known, however, that children with normal hearing begin developing emergent literacy skills, such as phonological awareness, well before their formal literacy instruction begins. ${ }^{10-13)}$ Despite the importance of phonological awareness on later reading skills among young hearing children, little is known about the development of phonological awareness skills in children with cochlear implants.

There are four related factors that indicate that the phonological awareness skills of young children with cochlear implants might be an area of special weakness and an area in great need of investigation. First, the primary goal of cochlear implantation is to provide children with an ability to perceive speech, thus allowing them to develop oral language and literacy abilities. However, cochlear implants cannot fully normalize children's auditory experiences, and children with cochlear implants typically demonstrate deficiencies in speech 
perception. ${ }^{14,15)}$ Indeed, the speech perception skills of children with cochlear implants have been documented as being equivalent to the speech perception skills of hearing aid users with severe hearing loss. ${ }^{8,16)}$ Second, children with cochlear implants typically remain delayed in the acquisition of speech and language skills. Specifically, the speech production skills of children with cochlear implants are often significantly delayed, even after the children have had years of experience with their cochlear implant, and even when they are compared to younger children whose age is matched with the deaf children's duration of cochlear implant experience. ${ }^{17,18)}$ Similarly, oral language is often not age-appropriate in young children with cochlear implants prior to school entry. ${ }^{7)}$ Third, among hearing preschoolers, these skills (speech perception, speech production, and oral language) are correlated with the phonological awareness abilities. ${ }^{19-27)}$ Additionally, recent studies have indicated that the phonological awareness abilities of schoolage children with cochlear implants are delayed in comparison to those of their peers with normal hearing., ${ }^{5,6,28,29)}$ Taken together, these factors place children with cochlear implants at significant risk for educationally relevant delays in the development of phonological awareness skills.

This study was designed to assess whether very early access to speech sounds provided by the early cochlear implantation would enable children to develop age-appropriate phonological awareness abilities in their preschool and school years. Additionally, this study examined whether children with cochlear implantation before 18 months of age will develop better phonological awareness skills than children with cochlear implantation at 18-36 months of age. This study also examined whether some factors like the child's age or sex would affect developing of age-appropriate phonological awareness abilities.

\section{Subjects and Methods}

\section{Participants}

The study group consisted of 30 children with normal hearing and 48 children with cochlear implant from both sexes equally. All of them were classified in three groups including preschool children (age: 60 to 71 months), children in first grade (age: 72 to 83 months) and children in second grade (age: 84 to 95 months).

All of the cochlear implanted (CI group) children were collected from normal children schools. Children were recruited for the study if they met the following criteria: 60 to 71 months of age for preschool, 72 to 83 months of age for first grade and 84 to 95 months of age for second grade, sensorineural hearing loss, utilization of a cochlear implant before age 3 , no additional disabilities, and no home language other than Farsi, having no treatment for phonological awareness. The group consisted of 24 females and 24 males. There were the same number of children per grade.

All the normal hearing children were assigned to the control group (NH group). All children in the $\mathrm{NH}$ group were reported as having passed a hearing screening or were screened for hearing loss. As with children in the CI group, participants in the NH group were 60 to 71 months of age for preschool, 72 to 83 months of age for first grade, and 84 to 95 months of age for second grade, had no additional disabilities, and lived in homes where the primary language was Farsi. The group consisted of 15 females and 15 males. There were the same number of children per grade.

\section{Procedure}

For children in both groups, one or two testing sessions lasting a total of approximately 1 hour were conducted at their schools. We have used the phonological awareness test of "Dastjerdi \& Soleimani", which is the phonological awareness test that has been standardized in Iran. This test consists of three subtests: phonemic awareness ${ }^{1}$, intra syllabic awareness $^{2}$, and syllabic awareness ${ }^{3}$. Before executing the phonological test, parents filled the acceptance form showing their approval of the procedure, afterwards we executed the phonological test.

\section{Stimuli}

The phonological awareness test has three categories including phonemic awareness that has seven subtests, intra syllabic awareness that has two subtests, and syllabic awareness that has one subtest.

\section{Execution of task}

Before executing the test, we communicated with the children. For each age group, we used special subtests. We explained each subtest with some guiding words that were at the beginning of each subtest. If the child could answer each question, he/she would get a score of 1 , but if he/she could not answer or his/her answer were wrong he/she would get a score of 0 . Although we did not help the child in giving the correct answers, we encouraged her/him to stay active throughout the entire test.

The subtests consisted of syllable segmentation, alliteration recognition, rhyme recognition, synthesis of phonemes,

\footnotetext{
${ }^{1}$ The awareness to focus on and manipulate individual phonemes in spoken words.

${ }^{2}$ The awareness to separate a word to onset and rhyme or alliteration and entire part of the word.

${ }^{3}$ The awareness to divide a word to its related syllables.
} 
recognizing words with similar beginning phoneme, recognizing words with similar ending phoneme, phoneme segmentation, recognizing the ending phoneme, deleting it and then uttering it, deleting middle phoneme, recognizing the beginning phoneme, deleting it and then uttering it.

\section{Results}

Data collected from this study was analyzed with two nonparametric statistical methods: Mann-Whitney and KruskalWallis to determine the relationship between phonological awareness and the child's audition. The results showed that the mean of phonological awareness in children with cochlear implants had a statistically significant difference from normal children $(p<0.05)$ (Table 1).

The comparison of results showed that sex had no significant effect, but age had a significant effect on phonological awareness scores. Therefore, older children would gain higher scores (Table 2).

Another important evaluated variable was the age of implantation. As shown in Table 3, there was a relationship between the age of implantation and phonological awareness scores. Children with a lower age of implantation had higher phonological awareness scores.

\section{Discussion}

The results show that the functions of the cochlear implant-

Table 1. Comparison between phonological awareness of the two groups

\begin{tabular}{clccc}
\hline & Audition type & $\mathrm{n}$ & Mean & $\mathrm{p}$ \\
\hline Phonological & Normal hearing & 30 & 9.47 & $<0.001$ \\
awareness & Cochlear implant & 48 & 8.82 & \\
\hline
\end{tabular}

ed children in phonological awareness skills are significantly lower than the normal hearing children. These results are similar to the previous studies. ${ }^{5,6,28,29)}$ In these studies, cochlear implanted children also experienced some problems with phonological awareness skills.

As shown above, there is a relationship between age of implantation and phonological awareness. Children with lower age of implantation would get better results because of their fast development. In many countries all over the world, doctors try to implant these prostheses before 1-year-of-age. In our country (Iran), we have some problems in achieving this goal. So we could find more children who got implantation before 18 months of age and we chose this criterion to divide children. The children with lower age of implantation gained higher scores and had better function. These results are similar to previous findings. ${ }^{30)}$ Other studies also reported that early auditory experience has a better effect on linguistic skills. ${ }^{31,32)}$ Therefore, we can now emphasize the advantage of early usage of cochlear implantation on children's language functions.

As we mentioned above, the child's age has significant effect on phonological awareness scores because this ability is related to literacy acquisition, therefore older children would gain higher scores. However, in this study, the difference between ages 5 and 7 years were more distinguishable in the cochlear implanted group. Although in the cochlear implanted group of children, differences between these age groups are statistically significant ( $p=0.003)$, in the normal hearing group of children, differences were not statistically significant $(p=$ 0.09). Although there were significant differences between the phonological awareness scores of the two groups (CI group, $\mathrm{NH}$ group), these results were statistically significant in only some of the subtests. The only subtest with significant difference was phoneme awareness.

Table 2. Comparison between mean of phonological awareness in the age groups

\begin{tabular}{|c|c|c|c|c|}
\hline & Audition type & Age (yrs) & Mean & $p$ \\
\hline & & 5 & 8.395 & \\
\hline & Cochlear implant & 6 & 8.812 & 0.003 \\
\hline & & 7 & 8.956 & \\
\hline & & 5 & 9.316 & \\
\hline \multirow[t]{5}{*}{ Phonological awareness } & Normal hearing & 6 & 9.457 & 0.092 \\
\hline & & 7 & 9.64 & \\
\hline & & 5 & 8.885 & \\
\hline & Between groups & 6 & 9.134 & 0.01 \\
\hline & & 7 & 9.298 & \\
\hline
\end{tabular}

Table 3. Comparison between the age of implantation and phonological awareness scores $(n=48)$

\begin{tabular}{|c|c|c|c|c|}
\hline Variable & Age of implantation & $n$ & Mean & $p$ \\
\hline \multirow{2}{*}{ Phonological awareness } & Before 18 months & 24 & 9.036 & \multirow{2}{*}{$<0.001$} \\
\hline & After 18 months & 24 & 8.406 & \\
\hline
\end{tabular}


According to the present and prior results, cochlear implantation prostheses have some problems in facilitating the acquisition of the phonological awareness. However, by the increase in the child's experience in utilizing this prostheses, better results are gained. Younger implanted children have better function in phonological awareness test. Since we know that phonological awareness is a significant skill for acquiring formal literacy skills, we should allocate some sessions to the treatment of these skills in our schedule.

\section{Conclusion}

We conclude from this study that children with lower age of implantation got better scores in phonological awareness test than children with higher age of implantation. But they were outperformed by their normal hearing peers in this area, especially in phonemic awareness.

We also conclude that phonological awareness skills would improve by child's growth and females scores did not differ from males scores.

\section{Acknowledgments}

This study was a part of a M.S thesis entitled "Study of phonological awareness of preschool and school aged children with cochlear implant and normal hearing" supported by Tehran University of Medical Science.

\section{REFERENCES}

1) Crosson J, Geers A. Analysis of narrative ability in children with cochlear implants. Ear Hear 2001;22:381-94.

2) Geers AE. Speech, language, and reading skills after early cochlear implantation. Arch Otolaryngol Head Neck Surg 2004;130:634-8.

3) Moeller MP. Early intervention and language development in children who are deaf and hard of hearing. Pediatrics 2000;106:E43.

4) Spencer LJ, Barker BA, Tomblin JB. Exploring the language and literacy outcomes of pediatric cochlear implant users. Ear Hear 2003; 24:236-47.

5) DesJardin JL, Ambrose SE, Eisenberg LS. Literacy skills in children with cochlear implants: the importance of early oral language and joint storybook reading. J Deaf Stud Deaf Educ 2009;14:22-43.

6) Schorr EA, Roth FP, Fox NA. A comparison of the speech and language skills of children with cochlear implants and children with normal hearing. Commun Disord Q 2008;29:195-210.

7) Geers AE, Moog JS, Biedenstein J, Brenner C, Hayes H. Spoken language scores of children using cochlear implants compared to hearing age-mates at school entry. J Deaf Stud Deaf Educ 2009;14:37185 .

8) Sarant JZ, Holt CM, Dowell RC, Rickards FW, Blamey PJ. Spoken language development in oral preschool children with permanent childhood deafness. J Deaf Stud Deaf Educ 2009;14:205-17.

9) Geers AE. Factors affecting the development of speech, language, and literacy in children with early cochlear implantation. Lang Speech Hear Serv Sch 2002;33:172-83.

10) Bradley L, Bryant PE. Categorizing sounds and learning to read-a causal connection. Nature 1983;301:419-21.

11) Chaney C. Preschool language and metalinguistic skills are links to reading success. Appl Psycholinguist 1998;19:433-46.

12) Lonigan CJ, Burgess SR, Anthony JL, Barker TA. Development of phonological sensitivity in 2- to 5-year-old children. J Educ Psychol 1998;90:294-311.

13) Wood C, Terrell C. Preschool phonological awareness and subsequent literacy development. Educational Psychology 1998;18:253-74.

14) Kirk KI, Miyamoto RT, Ying EA, Perdew AE, Zuganelis H. Cochlear implantation in young children: effects of age at implantation and communication mode. Volta Review 2000;102:127-44.

15) Miyamoto RT, Osberger MJ, Todd SL, Robbins AM, Stroer BS, Zimmerman-Phillips $\mathrm{S}$, et al. Variables affecting implant performance in children. Laryngoscope 1994;104:1120-4.

16) Eisenberg LS, Kirk KI, Martinez AS, Ying EA, Miyamoto RT. Communication abilities of children with aided residual hearing: comparison with cochlear implant users. Arch Otolaryngol Head Neck Surg 2004;130:563-9.

17) Chin SB, Kaiser CL. Measurement of articulation in pediatric users of cochlear implants. Volta Review 2000;102:145-56.

18) Chin SB. Children's consonant inventories after extended cochlear implant use. J Speech Lang Hear Res 2003;46:849-62.

19) Bird J, Bishop DV, Freeman NH. Phonological awareness and literacy development in children with expressive phonological impairments. J Speech Hear Res 1995;38:446-62.

20) Chaney C. Language development, metalinguistic awareness, and emergent literacy skills of 3-year-old children in relation to social class. Appl Psycholinguist 1994;15:371-94.

21) McBride-Chang C. Phonological processing, speech perception, and reading disability: an integrative review. Educ Psychol 1995;30:10921.

22) Metsala JL. Young children's phonological awareness and nonword repetition as a function of vocabulary development. J Educ Psychol 1999;91:3-19.

23) Preston JL, Edwards ML. Speed and accuracy of rapid speech output by adolescents with residual speech sound errors including rhotics. Clin Linguist Phon 2009;23:301-18.

24) Rvachew S, Ohberg A, Grawburg M, Heyding J. Phonological awareness and phonemic perception in 4-year-old children with delayed expressive phonology skills. Am J Speech Lang Pathol 2003;12: 463-71.

25) Rvachew S, Grawburg M. Correlates of phonological awareness in preschoolers with speech sound disorders. J Speech Lang Hear Res 2006;49:74-87.

26) Silvén M, Niemi P, Voeten MJM. Do maternal interaction and early language predict phonological awareness in 3- to 4-year-olds? Cogn Dev 2002;17:1133-55.

27) Smith CL, Tager-Flusberg H. Metalinguistic awareness and language development. J Exp Child Psychol 1982;34:449-68.

28) James D, Rajput K, Brown T, Sirimanna T, Brinton J, Goswami U. Phonological awareness in deaf children who use cochlear implants. J Speech Lang Hear Res 2005;48:1511-28.

29) James D, Rajput K, Brinton J, Goswami U. Phonological awareness, vocabulary, and word reading in children who use cochlear implants: does age of implantation explain individual variability in performance outcomes and growth? J Deaf Stud Deaf Educ 2008;13:117-37.

30) Johnson C, Goswami U. Phonological awareness, vocabulary, and reading in deaf children with cochlear implants. J Speech Lang Hear Res 2010;53:237-61.

31) Nicholas JG, Geers AE. Effects of early auditory experience on the spoken language of deaf children at 3 years of age. Ear Hear 2006;27: 286-98.

32) Houston DM, Miyamoto RT. Effects of early auditory experience on word learning and speech perception in deaf children with cochlear implants: implications for sensitive periods of language development. Otol Neurotol 2010;31:1248-53. 